Fisheries Management and Ecology, 2002, v.9, n.2, p.105-110

ISSN: (Print 0969-997X) (Online 1365-2400)

DOI: $10.1046 / \mathrm{j} .1365-2400.2002 .00291 . \mathrm{X}$

The definitive version is available at www3.interscience.wiley.com

http://www.wiley.com/bw/journal.asp?ref=0969-997X

http://www3.interscience.wiley.com/cgi-bin/fulltext/118929226/PDFSTART

(C) 2002 Blackwell Science Ltd

\title{
Juvenile growth and survival of heat-shocked triploid hybrid saugeyes, Stizostedion vitreum $\times$ S. canadense
}

\author{
M.A.R. Garcia-Abiado, W.E. Lynch Jr, K. Dabrowski, S. Czesny \& J. Rinchard \\ School of Natural Resources, The Ohio State University
}

\section{J. Stafford}

Ohio Department of Natural Resources, Hebron State Fish Hatchery

\begin{abstract}
Triploid hybrid saugeyes may be a desirable stocking alternative because diploid saugeyes are fertile and can compromise the genetic integrity of parental stocks. Four groups of saugeye eggs were heat-shocked 5 min after fertilization for $15 \mathrm{~min}$ at $31^{\circ} \mathrm{C}$, which resulted in an $86.7 \pm 9.4 \%$ triploidy rate and $57.8 \pm 24.3 \%$ survival to the eyedstage. Heat shocked and control saugeyes were stocked in two ponds for 40 days at 395000 ind. ha $^{-1}$. Mean length and weight of triploid and heat-shocked diploid saugeyes were greater $(P<0.01)$ than unshocked diploid saugeyes. Survival of heat-shocked saugeyes $(22.4 \%)$ was lower than unshocked saugeyes $(94.7 \%)$. Heat-shocked fish $(n=25851)$ harvested from ponds were stocked for 153 days in O'Shaughnessy Reservoir, Ohio, USA. Triploids were 34 mm shorter and weighed $41 \mathrm{~g}$ less than heat-shocked diploids $(P<0.01)$. Mean length and weight of triploids were comparable with unshocked diploids elsewhere in Ohio.
\end{abstract}

\section{Introduction}

Hybrid saugeyes, Stizostedion vitreum Mitchill $\times$ S. canadense Smith, are important sport fish in Ohio, and 5-10 million, 2-month-old saugeyes are stocked annually in reservoirs and lakes [R. Petering, Ohio Department of Natural Resources (ODNR), personal communication]. Saugeye reproduction in the Ohio River (White \& Schell 1995), Normandy Reservoir, Tennessee (Fiss, Sammons, Bettoli \& Billington 1997), and in the Peoria Pool of the Illinois River (Billington, Brooks \& Heidinger 1997) appeared to have compromised the genetic integrity of parental stocks by producing second generation hybrids. Fisheries managers and aquaculturists have utilized triploidy induction as a sterilization technique (Donaldson \& Devlin 1996; Benfey 1999) to prevent genetic contamination of parental stocks by fertile fish hybrids such as hybrid striped bass (striped bass, Morone saxatilis Walbaum $\times$ white bass $M$. chrysops Rafinesque reciprocal hybrids; Curtis, Sessions, Bury, Rezk \& Dunham 1987; Kerby, Everson, Harrell, Starling, Revels \& Geiger 1995), hybrid sunfish (female green sunfish Lepomis cyanellus Rafinesque $\times$ male bluegill L. macrochirus Rafinesque; Wills, Paret \& Sheehan 1994) and hybrid saugeyes (female walleye Stizostedion vitreum Mitchill $\times$ male sauger S. canadense Smith; Garcia-Abiado, Lynch, Dabrowski \& Hartman 2001). Hence, the use of sterile triploid saugeyes may be desirable in fisheries management and conservation, provided $100 \%$ triploid saugeyes are stocked and survival and growth of fish are good.

Heat shock is the most common physical shock used to induce triploidy in fishes because techniques are straightforward and large volumes of eggs can be shocked at any one time. However, several growth and survival studies of triploid fishes produced by heat shock revealed poorer performance compared with their diploid counterparts [Oncorhynchus mykiss (Walbaum) (Guo, Hershberger \& Myers 1990); yellow perch Perca flavescens Mitchill (Malison, Procarione, Held, Kayes \& Amundson 1993); common carp Cyprinus carpio L. (Cherfas, Gomelsky, Ben-Dom, Peretz \& Hulata 1994)]. The performance of triploid hybrid saugeyes in ponds and reservoirs is 
important to determine the practicality of using these fish for stocking programmes in Ohio and elsewhere. This study evaluated the juvenile growth and survival of heat-shocked, triploid hybrid saugeyes in ponds and in one Ohio reservoir.

\section{Materials and methods}

Source of gametes

Walleye eggs were stripped on 2 April 1998 from ovulated females caught from C.J. Brown Reservoir, Ohio. Unfertilized eggs were placed in a plastic bag maintained at $9-10{ }^{\circ} \mathrm{C}$ in a cooler with ice, and transported (90 min) to the Ohio State University Aquaculture Laboratory, Columbus, Ohio. Spermatozoa were collected from four sauger males originally caught from the Ohio River. The males were maintained in 400-L flow-through tanks at the Aquaculture Laboratory until sperm collection. Undiluted sperm was stored on ice and used within $1 \mathrm{~h}$.

\section{Artificial fertilization and heat shock}

Eggs and sperm were mixed for $1 \mathrm{~min}$ and then washed in tannic acid (Sigma Chemical Co., St Louis, MO, USA) at $400 \mathrm{mg} \mathrm{L}^{-1}$ for $3 \mathrm{~min}$ to remove egg adhesiveness. Sperm to egg ratio was about $1 \mu \mathrm{L}$ sperm to $1 \mathrm{~mL}$ eggs. Four separate groups of fertilized eggs (three groups of $1 \mathrm{~L}$ and one group of $0.45 \mathrm{~L}$ ) were heat-shocked at $31.0 \pm 0.1{ }^{\circ} \mathrm{C}$ starting $5 \mathrm{~min}$ after fertilization for $15 \mathrm{~min}$. These parameters were based upon high (> 80\%) triploid rates achieved from preliminary triploidy experiments during the 1997 spring spawning season (data not shown). Another $1 \mathrm{~L}$ of eggs obtained from the same lots used for heat-shock was used as a diploid control. Random samples of 200-400 eggs from each group were incubated in individual egg baskets in California hatching trays until the eyed stage. The four heat-shocked groups of eggs were pooled $(3.45 \mathrm{~L})$ and transported $(45$ min) in water to Hebron State Fish Hatchery, Hebron, Ohio for incubation in McDonald jars, separately from the $1 \mathrm{~L}$ of control eggs. Eggs were treated once daily with 50-100 p.p.m. formaldehyde starting on the second day after fertilization to prevent fungal growth.

\section{Pond and reservoir evaluation}

On 16 April 1998, newly hatched larvae from both control and heat-shocked groups were stocked into four ponds (heat-shocked: ponds 1 and 2; control: ponds 3 and 4) at a rate of 395000 ind. ha ${ }^{-1}$. Ponds 2 and 3 are both 0.1 ha and ponds 1 and 4 are 0.26 and 0.20 ha, respectively. These ponds were fertilized weekly following standard fertilization procedures for saugeyes (Culver 1996). Water temperature $\left(18.2 \pm 3.6{ }^{\circ} \mathrm{C}\right)$, dissolved oxygen concentration $\left(11.1 \pm 3.6 \mathrm{mg} \mathrm{L}^{-1}\right)$, and Secchi depth $(0.7 \pm 0.2 \mathrm{~m})$ were considered normal during the 40 days of rearing. On 26 May 1998 (after 40 days), heat-shocked and control fish were harvested by completely draining the four ponds. The fish from each pond were transferred to four individual raceways. From each raceway, 30-40 fish were randomly sampled and transported live to the laboratory for length and weight measurements and for ploidy analyses. On 27 May 1998, ODNR stocked 25851 heat-shocked saugeyes [18 904 from pond 1 (62.5\% triploids) and 6947 from pond 2 (86.7\% triploids); 69\% weighted mean triploidy] into O'Shaughnessy Reservoir, Ohio where saugeye growth has been historically high because of very high gizzard shad, Dorosoma cepedianum Lesueur, prey densities. On 27 October 1998 (after 153 days), 23 fish were collected by standard electric fishing procedures to determine weight, total length (TL, mm), ploidy and sex.

\section{Survey of reservoirs stocked with diploid saugeyes}

Age-0 saugeye data from seven Ohio reservoirs in 1998 were summarized to compare qualitatively the performance of triploids and heat-shocked diploids from O'Shaughnessy Reservoir with normal diploids. These reservoirs were stocked by ODNR from 24 to 30 May, 1998 as part of their annual saugeye stocking programme. During autumn, 20-30 individuals of age-0 saugeyes 
were collected by electric fishing.

Ploidy analysis by flow cytometry

Ploidy of samples (embryos or blood) was determined by flow cytometry following techniques described previously (Lin \& Dabrowski 1996; Garcia-Abiado et al. 2001).

\section{Results}

Triploidy induction

Heat shock at $31{ }^{\circ} \mathrm{C}$ applied 5 min after fertilization for $15 \mathrm{~min}$ to four groups of fertilized saugeye eggs resulted in a mean triploidy rate of $86.7 \pm 9.4 \%$ (mean $\pm \mathrm{SD}$ ) and survival to the eyedstage of $57.8 \pm 24.3 \%$. The controls ( $100 \%$ diploids) had $71 \%$ survival to the eyed-stage.

\section{Pond evaluation}

Heat-shocked saugeye larvae averaged $8.8 \pm 0.5 \mathrm{~mm}$ TL and $4.3 \pm 0.05 \mathrm{mg}$ prior to stocking into ponds 1 and 2. Control saugeyes averaged $8.5 \pm 0.5 \mathrm{~mm} \mathrm{TL}$ and $4.0 \pm 0.40 \mathrm{mg}$ prior to stocking. As larval saugeyes were collected from the raceways, some heat-shocked fish were motionless, lying on the bottom of the transport bags. All diploid control larvae were up in the water column inside the bags. At harvest after 40 days, survival for normal diploids was estimated at $89 \%$ and $100 \%$ in the two control ponds (Table 1). Survival was $22 \%$ for both ponds stocked with heatshocked fish. These survival rates resulted in an estimated final density of $360000 \mathrm{ind}^{\text {. ha }}{ }^{-1}$ in the control ponds, but only $90000 \mathrm{ha}^{-1}$ in the ponds stocked with heat-shocked fish. Triploidy rates in ponds 1 and 2 after 40 days were 62.5 and 86.7\%, respectively. The unshocked saugeyes from the two control ponds were $100 \%$ diploids $(n=30)$. Mean length and weight of triploid and heatshocked diploid saugeyes from ponds 1 and 2 were greater (ANOVA; $P<0.01$ ) than for normal diploid saugeyes in the control ponds and likely reflects the large differences in fish density between the experimental and control ponds (Table 1). Comparison of triploid fish with heat-shocked diploid fish revealed significant differences between the two ploidy groups in pond 1 but not pond 2 (Table 1; Fig. la \& b). In pond 1, heat-shocked diploids were longer and heavier (ANOVA: $P<0.01$ ) than triploids. Two distinct size groups of heat-shocked diploid fish occurred in pond 1: a group ranging from 43 to $48 \mathrm{~mm}$ TL, which was similar in size to the triploids; and a second group that ranged from 59 to $78 \mathrm{~mm}$ TL.

\section{Reservoir evaluation}

In O'Shaughnessy Reservoir, triploids were smaller in autumn compared with heat-shocked diploids (Table 2; independent samples $t$-test; $P<0.05$ ). Similar results were obtained when only females were compared (Table 2). Although triploids were $34 \mathrm{~mm}$ shorter in length and weighed 41 g less, considerable size overlap occurred between the two ploidy groups (Fig. lc). Heat-shocked diploids in O'Shaughnessy Reservoir were 30-50 mm longer and 30-50 g heavier than normal diploids from other Ohio reservoirs (Table 2), which likely reflects the collection date being 7-25 days later than other reservoirs. Although triploids were significantly smaller than their shocked conspecifics in O'Shaughnessy Reservoir, mean length and weight of triploids were comparable with normal diploids elsewhere in Ohio.

\section{Discussion}

Substituting triploid saugeyes for diploid saugeyes in stocking programmes to protect parental genetic stocks requires that two criteria be met. First, the method of induction must produce $100 \%$ triploids and second, the method should be reliable to produce uniform results among shocked egg batches. Additionally, management agencies would prefer acceptable survival across all life stages and that either growth in triploids will equal or exceed that of diploids, or triploid growth will 
be only marginally slower than diploids. This study contributes towards assessing these needs.

Heat shock failed to produce $100 \%$ triploid saugeyes. Stocking 10 million fingerlings from these groups, for example, would potentially introduce about 77 000-2.6 million heat-shocked diploids capable of backcrossing with either parental species.

Incubation survival of each group of eggs after heat shock varied 23.2-79.6\%, although the eggs and sperm from several broodstock were pooled prior to heat shock. Three of the four egg groups heat-shocked had survival of $61.3-79.6 \%$, which is probably acceptable from a hatchery production standpoint, although greater than $70 \%$ survival in all egg batches is preferred. Survival of triploid larvae was $22 \%$ in each of the two production ponds. In the O'Shaughnessy Reservoir, the estimated triploid percentage at time of stocking and autumn sampling was 69.0 and 52.2\% (12 triploids of 23 fish sampled), respectively. More survival comparisons in ponds and reservoirs for several years are required to make conclusions on survival of heat-shocked triploids.

Table 1. Triploidy rate $(\%)$, pond survival $(\%)$, and mean $( \pm$ SD) total length $(\mathrm{mm})$, weight $(\mathrm{g})$ of heat-shocked (ponds 1 and 2) and control (ponds 3 and 4) saugeye stocked into ponds at the Hebron State Fish Hatchery, Ohio. HS 2n denotes heat-shocked diploids, HS 3n denotes triploids, and $2 \mathrm{n}$ denotes normal diploids

\begin{tabular}{|c|c|c|c|c|c|c|}
\hline \multirow[b]{2}{*}{ Variable } & \multicolumn{2}{|c|}{ Pond 1} & \multicolumn{2}{|c|}{ Pond ? } & \multirow{2}{*}{$\frac{\text { Pond } 3}{2 n}$} & \multirow{2}{*}{$\frac{\text { Pond } 4}{2 n}$} \\
\hline & $\operatorname{HS} 2 \pi$ & HS 3n & HS $2 \pi$ & HS $3 \pi$ & & \\
\hline Triploidy (\%) & \multicolumn{2}{|c|}{62.5} & \multicolumn{2}{|c|}{86.7} & 0.0 & 0.0 \\
\hline Pond survival $(\%)$ & \multicolumn{2}{|c|}{22.3} & \multicolumn{2}{|c|}{22.5} & 89.4 & 100.0 \\
\hline Meann length (mm) & $61,0 \pm 13,2^{4}$ & $42.7 \pm 3.4^{\mathrm{b}}$ & $46.5 \pm 5.7^{b}$ & $45.9 \pm 3.3^{\mathrm{b}}$ & $31.0 \pm 1.3^{\mathrm{i}}$ & $36.1 \pm 1.8^{\mathrm{c}}$ \\
\hline Mean weight (g) & $1.83 \pm 1.10^{\mathrm{a}}$ & $0.51 \pm 0.14^{\mathrm{b}}$ & $0.65 \pm 0.20^{\mathrm{b}}$ & $0.60 \pm 0.14^{\mathrm{b}}$ & $0.19 \pm 0.03^{\mathrm{d}}$ & $0.30 \pm 0.03^{c}$ \\
\hline
\end{tabular}

Mean lengths and weights with the same letter superscripts are not significantly different $(P>0.05)$.

Differences in prey density as a result of low survival of heat-shocked fish in two ponds does not allow unbiased comparison of growth rates between heat-shocked triploids and unshocked diploids. For example, the densities of unshocked diploids in the two ponds were about four times more than densities of heat-shocked fish in the other two ponds. These large differences in density probably resulted in unshocked diploids being about $15 \mathrm{~mm}$ shorter than their triploid conspecifics in adjacent ponds.

From a management perspective, the growth results provided encouraging aspects in the use of triploid saugeyes for replacing diploids in stocking programmes. Preferably, triploid growth would have been similar or exceeded diploid growth rates, whether it be the heat-shocked diploids or normal diploids in nearby reservoirs. This was not the case in the study, however, the growth of heat-shocked triploids may still be acceptable for recreational fisheries. Mean length and weight of triploids were about $86 \%$ and $64 \%$, respectively, of heat-shocked diploids in O'Shaughnessy Reservoir. The average autumn triploid length of $211 \mathrm{~mm}$ TL was comparable with 1998 growth of normal diploid saugeye juveniles throughout Ohio's reservoirs. Triploids should be stocked together with untreated diploids to determine the effects of different prey densities among reservoirs.

In summary, survival and growth of heat-shocked triploid saugeyes in ponds and a reservoir was provided. Because heat shock failed to induce $100 \%$ triploid saugeyes, the use of heat-shocked triploid saugeyes in stocking programmes will not protect the genetic integrity of parental stocks. Research should now focus on producing $100 \%$ triploid saugeyes by pressure shock (Garcia-Abiado et al. 2001) and evaluate their growth and survival in ponds and reservoirs. It is also critical to simultaneously compare triploid and diploid saugeye performance in ponds and additional reservoirs and ultimately, evaluate the fisheries created via triploid stocking. 

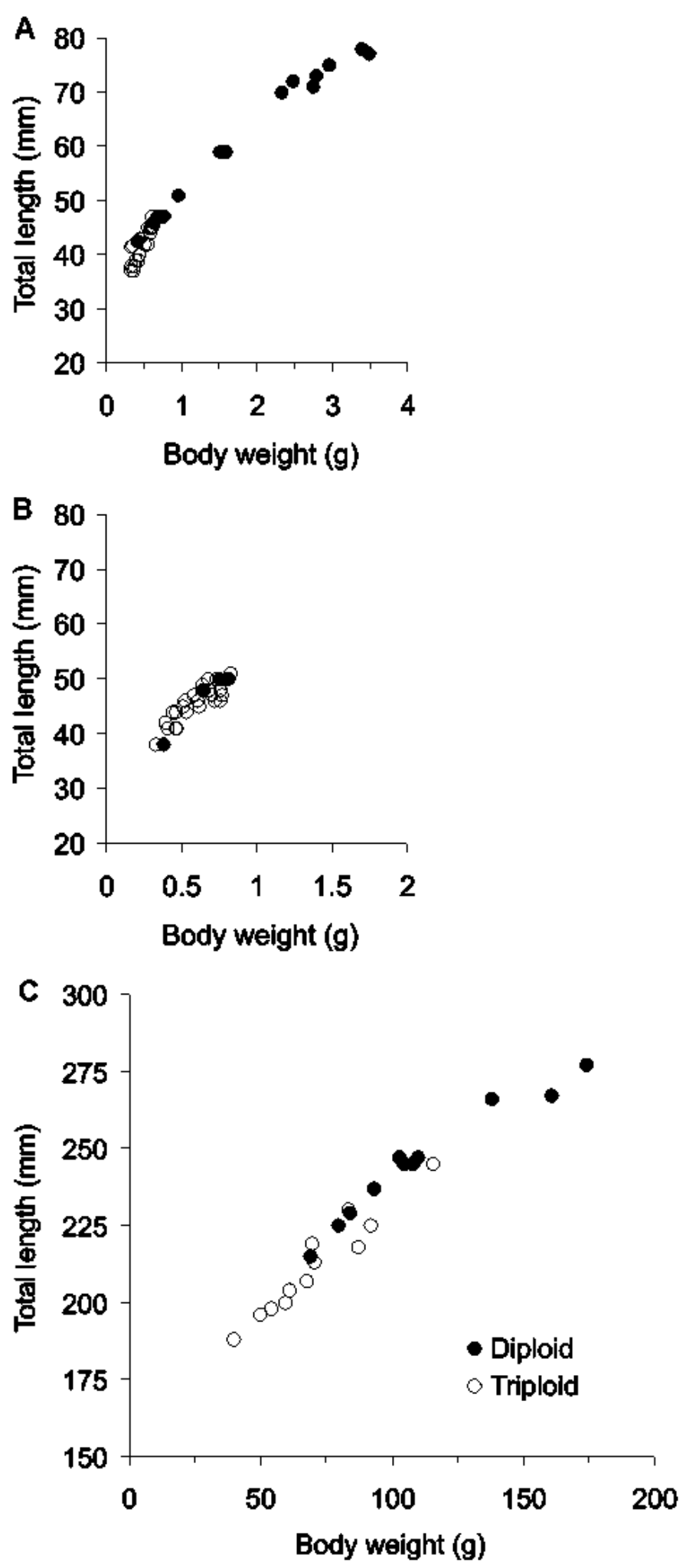

Figure 1. Length and weight of heat-shocked diploid and triploid saugeye reared in Hebron State Fish Hatchery and O'Shaughnessy Reservoir for 40 and 153 days, respectively. (A) Saugeye growth at Hebron State Fish Hatchery pond 1 ( $n=40 ; 15$ diploids, 25 triploids); (B) growth in pond 2 ( $n=30 ; 4$ diploids, 26 triploids); (C) saugeye growth at O'Shaughnessy Reservoir ( $n=23 ; 11$ diploids, 12 triploids). 
Table 2. Mean length and weight $( \pm \mathrm{SD}$ ) of heat-shocked triploid (five females, seven sexually undifferentiated fish) and diploid saugeye (nine females, two sexually undifferentiated fish) from O'Shaughnessy Reservoir, Ohio and for normal diploids from Ohio reservoirs sampled during autumn 1998 by the Ohio Department of Natural Resources, Division of Wildlife. O'Shaughnessy Reservoir was stocked on 27 May 1998 while other Ohio reservoirs were stocked during 24-30 May 1998. HS 2n denotes heat-shocked diploids, 3n denotes triploids, and $2 \mathrm{n}$ denotes normal diploids. All saugeye were collected with standardized electric fishing methods

\begin{tabular}{lccccc}
\hline Reservoir & Collection date & Ploidy & $n$ & Length (mm) & Weight (g) \\
\hline OShaughnessy & $27 / 10 / 1998$ & 3n (females) & 5 & $212.8 \pm 12.6$ & $67.7 \pm 11.1$ \\
& $27 / 10 / 1998$ & 3n (all) & 12 & $211.9 \pm 16.3$ & $70.8 \pm 20.9$ \\
& HS 2n (fennales) & 9 & $248.7 \pm 19.3$ & $116.8 \pm 34.5$ \\
Atwood & HS 2n (all) & 11 & $245.5 \pm 18.9$ & $111.3 \pm 33.4$ \\
Buckeye & $06 / 10 / 1998$ & $2 \mathrm{n}$ & 30 & $211.1 \pm 17.2$ & $76.7 \pm 18.8$ \\
Charles Mill & $20 / 10 / 1998$ & $2 \mathrm{n}$ & 30 & $236.0 \pm 24.8$ & $125.0 \pm 44.4$ \\
Clendening & $02 / 10 / 1998$ & $2 \mathrm{n}$ & 30 & $211.0 \pm 17.1$ & $88.1 \pm 21.7$ \\
Deer Creek & $15 / 10 / 1998$ & $2 \mathrm{n}$ & 28 & $200.1 \pm 23.9$ & $67.2 \pm 24.3$ \\
Hoover & $06 / 10 / 1998$ & $2 \mathrm{n}$ & 30 & $163.8 \pm 25.3$ & $31.1 \pm 20.8$ \\
Tappan & $16 / 11 / 1998$ & $2 \mathrm{n}$ & 20 & $236.2 \pm 24.7$ & $100.2 \pm 32.9$ \\
\hline
\end{tabular}

\section{Acknowledgments}

This research was funded by the Ohio Department of Natural Resources, Division of Wildlife under Federal Aid in Sport Fish Restoration Project F-69-P-5, Fish Management in Ohio. We thank Jeromy Applegate, Travis Hartman and Andrew S. Oberyszyn for technical assistance. Salaries were partly provided by support from state and federal funds to Ohio Agricultural Research and Development Center, The Ohio State University. We acknowledge The Ohio State University Comprehensive Cancer Center Analytical Cytometry Laboratory for assistance and support was provided in part by PHS NIH P30 CA-16058. We thank ODNR personnel for collecting saugeye samples from different reservoirs.

\section{References}

Benfey T.J. (1999) The physiology and behavior of triploid fishes. Reviews in Fisheries Science 7, 39-67.

Billington N., Brooks R.C. \& Heidinger R.C. (1997) Frequency and natural hybridization between saugers and walleyes in the Preoria Pool of the Illinois River, as determined by morphological and electrophoretic criteria. North American Journal of Fisheries Management 17, 220-224.

Cherfas N.B., Gomelsky B., Ben-Dom N., Peretz Y. \& Hulata G. (1994) Assessment of triploid common carp (Cyprinus carpio L.) for culture. Aquaculture 127, 11-18.

Culver D.A. (1996) Fertilization procedures for pond culture of walleye and saugeye. In: R.C. Summerfelt (ed.) Walleye Culture Manual. Ames, IA, USA: North Central Regional Aquaculture Center Publications Office, Iowa State University, pp. 115-122.

Curtis T.A., Sessions F.W., Bury D., Rezk M. \& Dunham R.A. (1987) Induction of polyploidy with hydrostatic pressure in striped bass, white bass, and their hybrids. Proceedings of the Annual Conference of the Southeastern Association of Fish and Wildlife Agencies 41, 66-69.

Donaldson E.M. \& Devlin R.H. (1996) Uses of biotechnology to enhance production. In: W. Pennell \& B.A. Barton (eds). Principles of Salmonid Culture. Amsterdam: Elsevier, pp. 969-1020.

Fiss F., Sammons C.S.M., Bettoli P.W. \& Billington N. (1997) Reproduction among saugeyes (F-x hybrids) and walleyes in Normandy Reservoir, Tennessee. North American Journal of Fisheries Management 17, $215-219$.

Garcia-Abiado M.A.R., Lynch W.E. Jr, Dabrowski K. \& Hartman T. (2001) Use of thermal and pressure shocks to induce triploid hybrid saugeyes. North American Journal of Aquaculture 63, 83-91.

Guo X., Hershberger W.K. \& Myers J.M. (1990) Growth and survival of intrastrain and interstrain rainbow trout (Oncorhynchus mykiss) triploids. Journal of the World Aquaculture Society 21, 250-256.

Kerby J.H., Everson J.M., Harrell R.M., Starling C.C., Revels H. \& Geiger J.G (1995) Growth and survival comparisons between diploid and triploid sunshine bass. Aquaculture 137, 355-358.

Lin F. \& Dabrowski K. (1996) Effects of sperm irradiation and heat shock on induction of gynogenesis in muskellunge (Esox masquinongy). Canadian Journal of Fisheries and Aquatic Sciences 53, 2067-2075.

Malison J.A., Procarione L.S., Held J.A., Kayes T.B. \& Amundson C.H. (1993) The influence of triploidy and heat and hydrostatic pressure shocks on the growth and reproductive development of juvenile yellow perch (Perca flavescens). Aquaculture 116, 121-133. 
White M.M. \& Schell S. (1995) An evaluation of the genetic integrity of Ohio River walleye and sauger stocks. In: H.L. Schramm Jr \& R.G. Piper (eds). Uses and Effects of Cultured Fishes in Aquatic Ecosystems. Bethesda, MD, USA: American Fisheries Society, Symposium 15, pp. 52-60.

Wills P.S., Paret J.M. \& Sheehan R.J. (1994) Pressure induced triploidy in hybrid Lepomis. Journal of the World Aquaculture Society 25, 507-511. 